\title{
Piggybacking the Traditional Coffee Ceremony as a Participatory Communication Strategy to Resolve Social Problems: an Assessment of Practices in Addis Ababa, Ethiopia
}

\author{
Anteneh Mekuria Tesfaye \\ Senior Instructor, Journalism and Communications Department \\ Faculty of Humanities \\ Bahir Dar University, Ethiopia \\ antenehm@bdu.edu.et
}

\begin{abstract}
This study explores how the Ethiopian traditional coffee ceremony serves women around Merkato, Addis Ababa as a forum for participatory communication to resolve child abuse and exploitation and other problems. In-depth interviews, focus group discussions(FGDs) and observations were used to gather data from participants, facilitators and the coordinator of the programme, run by Children Aid Ethiopia (CHAD-ET). Although the initiative gave chance for some women to discuss about some major problems of their area, the overall procedure did not seem to be in a position to give frolicsome atmosphere for all participants to take part in the discussions mainly because of the formal nature of communications, limited skills of facilitators and large group size. The agenda for discussions were set by CHAD-ET. As a result, the sessions were usually held to meet predetermined objectives. The fact that participants often prioritised other issues over what the sponsor organisation set shows that the target groups were not included in the programme planning and designing stage.
\end{abstract}

\section{Keywords}

Development communication, coffee ceremony, traditional communication systems, participatory communication, social problems 


\section{Introduction}

A growing body of literature in the field of development communication emphasised that community participation needs to be at the centre of development initiatives (Besseite, 2004; Diouf, 1995; Melkote and Steeves, 2001; Servaes, 1999). Some research findings also indicated the significance of community participation at the different stages of development programmes, especially in the decision making process (Narayan, 1996; Pretty et al. 1995; Kottak, 1991). Lack of participation among target groups or community members in either the planning, implementation or decision making process of development initiatives was also identified as one of the main reasons for the failures of some programmes (Chambers, 1997; cited in Mefalopulos, 2003; Fraser and Villet, 1994; Moemeka, 1997; Rietbergen-McCracken, 1996).

Given the increasing importance of participatory communication strategies, there has been a growing tendency among local and international development organisations towards promoting strategies which focus on societies' system of beliefs and pre-existing social structures. In fostering participatory communications among the grassroots, piggybacking traditionally and culturally used collective practices such as folk media, festivals, dances, etc have been seen by many as fitting ways for community involvement in a bid to identify and figure out multifaceted social problems in developing countries (Melkote, 1991; Mlama, 1991; Yoon, 2006). In Ethiopia, where the majority of the society is collectively oriented, the use of social rituals can play a significant role in promoting participatory communication strategies. Understanding this fact, a considerable number of governmental and nongovernmental organizations have been trying to use the Ethiopian traditional coffee ceremony to foster participatory problem-solving schemes at the grassroots level.

Even though a great deal of attention has been paid toward promoting participatory communication initiatives, less has been done in the direction of conducting empirical studies addressing issues related to implementation and effectiveness of the programmes. In a general context, although participatory communication strategies have been touted as the best methods by many development scholars, communication experts and policy makers, they have been 
criticised for failing to ensure genuine participation of the grassroots (Melekote and Steeves, 2001: 338).

This study set out to assess how the traditional coffee ceremony has been piggybacked as a participatory communication strategy to solve social problems by women living in and around Merkato, Addis Ababa. The study specifically endeavoured to answer the following questions: What was the participation of attendants like in the coffee ceremonies? What were the major topics or social problems rose in the discussions? Who set the agenda? And how? What did participants' representation look like in terms of religion, gender, ethnicity, class?

Before delving into the nature of participatory communication, a brief background about the problem, the Ethiopian traditional coffee ceremony and theoretical underpinnings will be presented, followed by the method of the study.

\section{Background of the problem}

Sexual abuse and exploitation of children is prevalent in Addis Ababa, although the magnitude of the problem is not well documented. Some small scale studies and the reports of national and international organizations', however, indicated that the problem has been on the increase (CSAEthiopia \& ORC Macro USA, 2005; Haberland, Chong, \& Bracken, 2003; UNICEF, 2001). The problem seems to be widespread in Merkato one of the slum neighborhoods in Addis Ababa where this and other social problems are rampantly observed.

This research focused on the coffee ceremony initiative which was a community based activity run by Children Aid Ethiopia (CHAD-ET) with the objective of enhancing community participation and involvement in the protection of children from sexual abuse and exploitation and to help the public discuss other major problems in the area. To achieve this objective, CHAD-ET selected 18 women volunteers from Addis Ketema sub-city women's association and trained them to facilitate discussions by arranging coffee ceremonies in and around Merkato, in nine Kebeles (small districts). Grassroots women in the area irrespective of their ethnic groups (Amhara, Oromo, Gurage, Gumze, Tigre etc) and their religions (Ethiopian Orthodox, Protestant, 
Muslims etc) were the target group of the coffee programme. This project has a three year life span and this research was conducted after the project has been run for two years.

\section{The Ethiopian Traditional Coffee Ceremony}

The Ethiopian traditional coffee ceremony, which is one of the most respected and colorful social rituals, gives the local people both a frivolous entertainment and congenial atmosphere to get together and discuss about various issues ranging from politics to minor personal issues. As an essential and an integral part of almost all Ethiopian social life coffee is drunk not only for its stimulating effect but also for getting together and having conversations.

While the coffee ceremony is liked and cherished by all people regardless of differences in culture, social class, age and sex, in many cases it is women who spend much of their time on it. Many women make coffee and call each other turn by turn and exchange information. In the Ethiopian society, where male chauvinism seems to exist, coffee ceremonies give women the chance of discussing issues with men relatively on equal basis.

\section{Theoretical Underpinnings}

\section{Trends in Development Communication}

The robust literature on development communication shows that the varied concepts and approaches in the field are categorised into two broad models - the diffusion and the participatory models. The diffusion model (Rogers, 1962) is based on a vertical, top-down and one-way model of communication which views communication as the transformation of new ideas and information from the developed countries to the 'underdeveloped' nations with the assumption of persuading people to change their attitudes and behaviors (Waisbord, 2001).

The participatory model, on the other hand, is characterised as two-way or horizontal communication which "stresses the importance of the cultural identity of local communities and of democratisation and participation at all levels - international, national, local and individual" (Servaes, 2008: 21). In this model, the goal of communication is "to involve and empower 
people in the definition, design and implementation process of development initiatives" (Mefalopulos, 2008: 57 - 58).

While there has been an argument among scholars concerning the appropriateness of the different models, the academic works in the last three decades have shown tremendous favoritism towards the participatory approach (Bessette, 2004; Mefalopulos, 2008; Melkote, 1991; Moemeka, 1997; Parfitt, 2004; Servaes, 1999). The key influential scholars of the diffusion model (Rogers, 1976) and (Schramm, 1979) eventual concession to revise the premises of the diffusion model by integrating the cultural and community needs of Third World countries and the overall paradigm shift in the field give way to participatory communication. The following part will draw attention to this approach.

\section{Participatory Communication}

Freire was among the first scholars who came up with the idea of participatory communication. In his seminal work Pedagogy of the oppressed (1970), he questioned the education system in Brazil which focused on persuading farmers to accept new innovations and proposed the idea of liberating education which conceptualised communication as free dialogue and participation that prioritised cultural identity, trust and commitment ( Freire, 1970).

At present, participatory communication has been widely favoured in the field of development communication despite the fact that it has not yet been perceived in the same way by scholars and practitioners. The difference starts with the nomenclature. Among the most renowned names are: the multiplicity paradigm (Servaes, 1991); the empowerment approach (Friedmann, 1992); another development (Jacobson, 1994; Melkote, 1991); the autonomous development (Carmen, 1996); and people-based development (cited in Mefalopulos, 2008: 51).

A considerable number of scholars and researchers of the field believe that defining the concept has been difficult (Arnst, 1996; Ascroft and Masilela, 1989 cited in Melkote 1991; Huesca, 2002; Jacobson and Storey, 2004; Servaes, 1999). Hence, both the theoretical and the practical aspects of participatory communication have been perceived in different ways. Pertaining to the 
conceptual approaches, for example, some scholars and practitioners conceived participation by emphasising on its "instrumental" value, that is by focusing on its role of facilitating development programmes and making them effective (Bordenave, 1994; 42 cited in Khadka, 2000; Stuart and Bery, 1996). Others practitioners use participatory communication as "transformative" which gives emphasis to empowering marginalised voices so that meaningful social changes can occur. Simply put, some consider participatory communication as a means to an end, while others perceive it as an end in itself. Still some others such as (Parfitt, 2004) take eclectic positions. With regard to this ambiguity, Parfitt (2004: 541) cogently explains that "Participation must function as a means because any development project must produce some outputs... but it must also function as an end inasmuch as empowerment is viewed as a necessary outcome". The author further elucidates that participation as a means does not address power differentials, while participation as an end has an emancipatory component in that it seeks to redress unequal power relations. This implies that taking participation as a means only does not guarantee genuine participation as it ignores the process and is most often used for a short period of time. Therefore, the use of participation both as a means and as an end seems to be essential for the effectiveness of development programmes.

Apart from participation as a means vs. end ambiguity, there exist contradictions in the different levels of participation. Some believe that participatory communication should focus at the local or grassroots level while others believe that it needs to be implemented at a large scale i.e. at the local, national and international levels (Servaes, 2008). Some believe that true participation must give communities the chance of making all decisions, while others believe that participation at other levels are also applicable.

The abovementioned differences on the names and the theories of participatory communication show that it is difficult to pin down the concept of participation in a single definition. According to Arnst (1996) the reason why participatory communication cannot be easily defined is that participation is an inherently dynamic phenomenon and contingent upon the context. Arnst (1996: 111) further lucidly states, "Authentic participation defines itself within each unique structural, social and cultural context as it unfolds." Taking the above varied forms of 
understanding into account one can discern that this failure of forming a clear cut notion on the theoretical aspect of participatory communication has somehow an effect on the practice.

Notwithstanding the varied names and conceptions of the concept, almost all the current mainstream scholars such as (Bessette, 2004; Jacobson, 1991; Mefalopulos, 2008; Melkote, 1991; Servaes, 1999) and others uphold "dialogue", "participation", "empowerment" and "twoway or horizontal communication" ,"grassroots participation" as the most important concepts in helping grassroots accentuate their real needs and problems.

\section{Typology of Participation}

As it has been noted, participatory communication does not always entail the same method or strategy to development work. It can be interpreted and applied in various degrees. Although there are different typologies or patterns of participation, for the purpose of this study, attention will be given to (Pretty's, 1995) classification of participation.

\section{Table 1. Pretty's (1995) typology of participation}

\begin{tabular}{|l|l|}
\hline Typology & \multicolumn{1}{|c|}{ Characteristics of each type } \\
\hline $\begin{array}{l}\text { Passive } \\
\text { Participation }\end{array}$ & $\begin{array}{l}\text { People participate by being told what is going to happen or has already } \\
\text { happened. It is a unilateral announcement by an administration or project } \\
\text { management without any listening to people's responses. The information } \\
\text { being shared belongs only to external professionals. }\end{array}$ \\
\hline $\begin{array}{l}\text { Participation } \\
\text { in Information } \\
\text { giving }\end{array}$ & $\begin{array}{l}\text { People participate by answering questions posed by extractive researchers } \\
\text { using questionnaire surveys or similar approaches. People do not have the } \\
\text { opportunity to influence proceedings, as the findings of the research are } \\
\text { neither shared nor checked for accuracy. }\end{array}$ \\
\hline $\begin{array}{l}\text { Participation } \\
\text { by } \\
\text { consultation }\end{array}$ & $\begin{array}{l}\text { People participate by being consulted, and external agents listen to views. } \\
\text { These external agents define both problems and solutions, and may modify } \\
\text { these in the light of people's responses. Such a consultative process does not } \\
\text { concede any share in decision-making, and professionals are under no } \\
\text { obligation to take on board people's views. }\end{array}$ \\
\hline $\begin{array}{l}\text { Participation } \\
\text { for material } \\
\text { incentive }\end{array}$ & $\begin{array}{l}\text { People participate by providing resources, e.g. labour, in return for food, } \\
\text { cash or other material incentives. Much on-farm research falls in this } \\
\text { category, as farmers provide the fields but are not involved in the } \\
\text { experimentation or process of learning. It is very common to see this called } \\
\text { participation, yet people have no stake in prolonging activities when the } \\
\text { incentives end. }\end{array}$ \\
\hline
\end{tabular}




\begin{tabular}{|l|l|}
\hline $\begin{array}{l}\text { Functional } \\
\text { Participation }\end{array}$ & $\begin{array}{l}\text { People participate by forming groups to meet predetermined objectives } \\
\text { related to the project, which can involve the development or promotion of } \\
\text { externally initiated social organisation. Such involvement does not tend to be } \\
\text { at early stages or project cycles of planning, but rather after major decisions } \\
\text { have been made. These institutions tend to be dependent on external } \\
\text { initiators and facilitators, but may become self-dependent. }\end{array}$ \\
\hline $\begin{array}{l}\text { Interactive } \\
\text { Participation }\end{array}$ & $\begin{array}{l}\text { People participate in joint analysis, which leads to action plans and the } \\
\text { formation of new local institutions or the strengthening of existing ones. It } \\
\text { tends to involve interdisciplinary methodologies that seek multiple } \\
\text { objectives and make use of systematic and structured learning processes. } \\
\text { These groups take control over local decisions, and so people have a stake in } \\
\text { maintaining structures or practices }\end{array}$ \\
\hline melf- & $\begin{array}{l}\text { People participate by taking initiatives independent of external institutions to } \\
\text { change systems. They develop contacts with external institutions for } \\
\text { resources and technical advice they need, but retain control over how } \\
\text { resources are used. Such self-initiated mobilisation and collective action may } \\
\text { or may not challenge existing inequitable distributions of wealth and power }\end{array}$ \\
\hline
\end{tabular}

(Pretty et al, 1995:61)

Table 1. Continued ...

In Pretty's (1995) typology, participation goes from passive, which is relatively considered as manipulative form of participation, to that of interactive and self-mobilisation which is considered to be genuine or authentic participation. This typology thus shows that participants' power will increase as they progress down to the last two stages whereas the power of external institutions or administrators may decrease at these last stages. Put simply, Pretty's typology gives a picture of a scale in which power shifts from the control of external institutions or administrators to that of a control by the people. According to this typology, self-initiated form of participation is viewed as the highest level of participation but this is not always the case. As Agarwal (2001) stated, all self-initiated participations should not be subsumed as a highest form of participation because in some cases some disadvantaged groups who do not have voice in one group may leave the group and form their own group but this newly self-initiated group could not be considered the highest form of participation.

\section{Traditional or Group Media}

As Mlama, (1991) pinpointed, in the past, alternative communication systems which are indigenous to African communities did not have a place in development communication. The 
main reason behind this is that group media which focus on the "interpersonal networks of communication were considered to be supportive of traditional structures and authority and hence were anti-development" (Melekote, 1991: 188).

Participatory approaches, however, have given due attention to alternative forms of communication which are culturally and historically attached with the life style of people living in the Third World. These communication systems, which have been called "alternative media", "group media", "small media", "community media", "traditional media", "falk media" etc, have been largely acknowledged by the growing body of literature. Ranganath (1980) lucidly explained that since the traditional media are part and parcel of the life style of the community, they are credible sources of information. They are typical and apt instruments for generating grassroots participation and dialogue. Also, they are relatively cheap and available in almost all cultures (in Melekot, 1991; 213). Boafo (2006) also stated that traditional media are not only trustworthy channels for information gathering, processing and disseminating but they also address local interests and concerns using local languages and cultural contexts.

Focusing on African countries (Moemeka, 1997\& 1998 and Faniran, 2008; Ugboajah, 1985) argued that good communication in Africa is viewed not in terms of its effect that can have on an individual, but to a great extent, it is viewed in terms of its capacity in building bonds of solidarity and integrating the individual into the group (cited in White, 2009). Ugboajah (1972: 60) elucidated that communication in the traditional societies of Africa has been taking place informally than in formal mechanisms. He noted that traditional media have forces and credibility to put stability into Africa's indigenous institutions.

Above all, studies have substantiated the importance of traditional communication systems for development. A study conducted by Khadka (2000) in Nepalese villages and Central Australian Aboriginal communities reveals that people prefer group media which allow them two-way interaction to the conventional expert- dominated and one way communication method. In Tanzania, dance as a group media draws a large audience especially women and serves as a forum for discussion and information exchange concerning issues such as dissatisfaction of 
communities with village leaders, scarcity of water, school girl pregnancy etc (Mlama, 1994). Indigenous communication systems such as ritual, singing, dance, and forum drama in Ghana were effectively used to gain the commitment of women to vaccination and other health practices (Riley, 2005). Melekot (1991) stated that many other studies in many Third World settings show that group media were effectively used in development initiatives such as family planning, health, harmony with neighbours etc.

Despite the growing recognition of their appropriateness for a range of development initiatives, if they are not used properly, group media in particular and participatory communication in general do have their own limitations. Mlama (1991) underscored that all indigenous media will not always provide an effective means of communication for development. Also participatory communications have been criticised for: ignoring that expediency may positively contribute to development; being failed to have similar relevance in all stages and maintain power inequalities; failing to give attention to the issue that people who lived in non-democratic societies might not participate out of fear of retaliation; promoting division, confusion, and disruption that do little to solve problems; not being clear on what participation entails because in some cases for example decisions are made by authorities and the participants may simply be asked to either implement or evaluate programmes (Waisbord 2001: 21 - 22).

These criticisms of participation show that participatory communication may not be always the solution for all development problems. Thus, as Tufte and Mefalopulos (2009: 19) noted, "a word of caution is called for as to the relevance, timeliness and content of proposed participatory strategies". Citing the advocates of participatory models, Waisbord further put forth the revised premises of participatory approaches which can respond to the aforementioned criticisms. Participatory approaches need to:

- be sensitive to the potential convenience of short-term and rapid solutions.

- recognise that recommendations for participation could also be seen as foreign and manipulative by local communities.

- be aware that the communities may be uninterested in spending time in democratic processes of decision-making and, instead, might prefer to invest their time on other activities. 
- recognise that communities are not necessarily harmonious and that participation may actually deepen divisions. Servaes (1996: 23) admits that "participation does not always entail cooperation nor consensus. It can often mean conflict and usually poses a threat to existent structures...Rigid and general strategies for participation are neither possible nor desirable."

- consider previous knowledge of problems and characteristics of a given community as these two are fundamental to identify activities and define projects.

(Waisbord 2001: 22 - 23)

Recognising these points would contribute to a better implementation of participatory development communication interventions.

\section{Method}

\section{Subjects and Sampling}

Qualitative research method was employed to explore what the facilitators (women who were assigned to facilitate discussions in the coffee ceremonies); the participants (marginalised women living in and around Merkato) and the coordinator (an employee in CHAD-ET who coordinates the programme) were doing and thinking. Seven facilitators (out of the total 18), 18 participants (the total number of participants was not known), and the only coordinator were selected as samples purposely. The facilitators were selected because they relatively facilitated discussions for a long time. Similarly, participants who attended the coffee ceremonies regularly and who belong to different social classes were selected as samples.

\section{Instruments}

To collect data, in-depth interviews, FGDs and observations were used. In-depth interview was used to amass data from the facilitators and the coordinator of the coffee programme. A total of eight interviews were made. Each interview session took more than one hour.

FGDs were made with 18 participants who were selected from three pre-existing coffee groups following the suggestions of Kitzinger (1994b). According to her, using pre-existing groups provide a social context within which ideas are formed and decisions are made. Consequently, three FGDs were made with three separate groups. The size - including six members in each FG- 
was determined consulting the guidelines of (Bloor et al, 2001; Finch and Lewis, 2003). Although the participants were selected from pre-existing coffee groups, attempts were made to include participants from different social classes, religion, ethnic and age groups in the composition. Each FGD took more than two hours.

Observations were made for the purpose of triangulation. Three coffee ceremony groups were selected and observed twice for the better understanding of the nature of communication. Both participants and facilitators were informed about the purpose of my presence before the formal observation sessions so that they would not act stiltedly.

\section{Procedure}

Prior to making the actual interviews and FGDs brief introductions were given to the selected samples about the purpose of this study. The selected subjects were also told some of the questions. Doing so helped them get prepared to the interview/FGD sessions psychologically. The interviews and the FGDs were administered in different Kebele halls using Amharic language, which is the national language of the country that the subjects of this study are using. This helped to avoid confusions and secure detailed information. The interviews and the FGDs were recorded using tape recorder with the consent of the participants.

\section{Data Analysis}

The data collected through the above described tools were transcribed, translated into English and then analyzed. First, the transcriptions of the three FGDs and the interviews were carefully examined and recurrent remarks given by the discussants and the interviewees were identified. Then, squeezing repeatedly expressed remarks, eight major themes were identified in terms of certain indicators (see Table 2). In order to reduce the subjectivity in identifying the implicated themes, the transcribed data were given to one more coder and inter-coder reliability was performed using Holsti method. The overall inter-coder reliability coefficient exceeded $.87(87.37 \%)$. The data from the observations were used under the identified themes using descriptions. The analyses were made by comparing the nature of participation in this initiative with that of the local coffee ceremonies that the researcher have observed at different times. 


\section{Analysis and Interpretation}

In order to figure out the nature of participatory communication, it is worthwhile to start with the procedure of the coffee ceremonies. The ceremonies, which were arranged for public participations by the help of CHAD-ET around Merkato, seemed to maintain the tradition as they follow the same procedures like the arrangement and use of traditional equipments, use of scented grasses, having three stages and accompanied by either popcorn or morsel of bread as snack. However, the nature of communication in these coffee ceremonies was quite different from the traditional ones mainly because of the formal nature of communication, facilitators and participants' misunderstanding of their roles, direction of information flow and large group size.

Table 2. Major themes implicated in the focus group discussions and in-depth interviews 


\section{Recurrent remarks (in 3 FGDs)}

Indicators

- Turn-taking

- Use of language/

$\checkmark$ Facilitators usually say they are going to teach us.... They always inform us to listen carefully

$\checkmark$ We are not allowed to speak without their permission

$\checkmark$ we are not as such open to talk different issues freely and informally as we do it at home with our close neighbours

$\checkmark$ It is just like formal meetings dominated by the leaders
Expression
- Sitting arrangements

- Methods used

- Facilitator-centered

$\checkmark$ They do not generate dialogue

$\checkmark$ Most often they do not encourage us to have our own say

$\checkmark$ Facilitators usually spend the coffee time by teaching us

$\begin{array}{ll}\checkmark & \text { We are always expected to listen } \\ \checkmark & \text { We rarely witness what we have observed around our villages }\end{array}$

$\checkmark$ It is in rare occasions that we were given the chance to share what we know...

$\checkmark$ They do not encourage us to reflect what we feel

$\checkmark$ Our role is to listen attentively and try to put what we have learnt in to practice
- Telling stories

- Reflecting

- Listening

- Taking active parts by asking questions,

- sharing information
- Passive participants

\section{Themes implicated}

- Formal communication $\checkmark$ We do not get information from other participants...

$\checkmark$ Facilitators do not give us the chance to ask questions

$\checkmark$ The communication process is usually from the facilitators to the participants

$\checkmark$ It is a bit frustrating to speak up in front of a large audience

$\checkmark$ The large sizes do not allow us to interact freely.

$\checkmark$ We are afraid of speaking in front of others

$\checkmark$ Most of us do not feel free to speak in front of large audiences
- Horizontal

- Vertical bottom-up

- Vertical top-down
- Top-down flow of information

- Number of participants

\section{- Very large groups}


$\checkmark$ Some of us do not feel we are in coffee places as we sit in rows

$\checkmark$ The Kebele halls do not allow us to sit in face-to-face

$\checkmark$ when facilitators brew the coffee near the roads we are disturbed by passersby

$\checkmark$ We dislike the places of the coffee ceremonies.
- Places of coffee - Inappropriate places ceremonies

$\checkmark$ Some of us do not feel that the topic is critical as there are other crucial issues

- Topic of discussions

- Mostly top-down

$\checkmark$ We often get information which help us change our view in relation to HIV/AIDS, child trafficking, sexual abuse and other issues from facilitators

$\checkmark$ Some participants sometimes change discussion topics

$\checkmark$ We usually learn about child abuse and exploitation.

$\checkmark$ The facilitators select their own topic

$\checkmark$ They start the sessions by giving us lectures about how we can protect children from abusers

- Way of setting agenda/topics of discussion

$\checkmark$ We are not asked to raise topics

$\checkmark$ It is the facilitators who usually came up with their own agenda. We participant in some cases to change the topics.

Table 2. Continued ... 
The data gathered using FGDs revealed that the participation in the coffee ceremonies took place in a more formal and solemn way. Most of the discussants characterized the communication process as firm and serious meetings. The observations also confirmed that the interactions were held in a very formal way. The opening remarks of the facilitators, their languages, the participants sitting arrangements showed that the interactions were made against the informal nature of communication which the participants have been experiencing in the traditional ceremonies. Such situations did not give chance to all participants to voice their ideas and feelings in the issues raised.

In utilising culturally pre-existing structures for participatory communication, the informal nature of communication seems to be taken for granted as it affirms the identity of the people as a community. In this initiative, although the coffee ceremony was used as a cultural framing for participatory process, the informal nature of communication, which is one of the main cultural elements, was missing. The project, therefore, had limitations because participants could not find the usual frolicsome atmosphere of the traditional ceremonies. Indeed, such formal meetings could be held taking any kind of beverage which does not require special ceremonies.

The other important aspect in evaluating the nature of participation is looking at the specific activities of both the facilitators and the participants. In relation to this, the data showed varied answers. The interviews with facilitators revealed that there were active interactions among the participants. Almost all facilitators said that they gave equal chance to all participants to reflect on the issues raised. Also, some of the participants of the FGDs reflected the same idea. However, many of the participants of the FGDs disagreed with the idea that facilitators give equal chance for all the participants. Most discussants stated that they never got the chance to ask questions during the coffee ceremonies. They mentioned that they were asking questions when the coffee ceremonies are over. According to these discussants, facilitators did not usually give chance to participants but when they rarely give, they give chance to those people who were relatively articulate enough or those who were able to express their thoughts freely. The discrepancy which was shown between the responses of participants who said facilitators gave equal chance and those who said facilitators did not give equal chance seems to emerge from the 
misunderstandings that participants had about the role of the facilitators in particular and the objective of the programme in general. Asked about the facilitators' roles, most of the FG discussants stated that the facilitators were supposed to 'teach' them about different problems of their area. The observations of the coffee ceremonies also revealed that facilitators did not give equal chance to all participants. In all the observed coffee ceremonies facilitators were merely telling stories for a long time and rarely gave chances to participants. For example, when they open sessions all the observed facilitators did not mention about ways of participations or discussions. They simply started the sessions using expressions like "Today we are going to learn...", "I will give you information..." Such introductory remarks did not show the manner in which participation would be carried out. They did not also try to pose thought provoking questions. They only gave chance to few participants just to ask and answer questions at the end of their speech. This activity of facilitators encouraged passive and superficial participation.

Since most of the times were covered by the information flow from the facilitators to the participants the communication process could somehow be seen as one-way. The only way which seemed to accommodate two-way communication was the sporadic questions and answers and the limited chances given to some participants to tell stories about what they have been observing in their areas. The majority of the participants were, however, spend the coffee times listening to what the facilitators and few participants were saying.

The formal nature of participation in the coffee ceremonies is attributed to lack of facilitators facilitating skills and to the presence of large number of participants. The following part will discuss these points.

It is obvious that having reasonable skills of facilitation is one of the essential elements which contribute to the success of participatory communications. In this regard as indicated earlier, facilitators lack this particular skill. One major problem is that, they did not seem to accept their roles as facilitators; they rather see themselves as 'teachers'. During the interviews almost all facilitators used "teaching" not "facilitating". Similarly, participants identified their respective facilitators as 'teachers'. 
In order for participants to share their experiences, thoughts, knowledge, facilitators need to engage all participants in discussions using different mechanisms, for instance, setting some tasks for discussions, making small groups, asking some thought provoking questions etc. As noted, facilitators were merely serving as transmitters of information. This goes against the idea of participatory model which shifts the role of development communicators from just serving as transmitters or disseminators of relevant information to that of facilitators of a process of social change capitalising on human learning at the individual and in community level (Codiz, 2005). Taking into account the socio-cultural factors, one can argue that mere dissemination of information by facilitators could be important as the community in the area lack information and knowledge which enable them to change their way of life. This may to some degree be true but these people have also their own indigenous knowledge which can be shared among themselves and put into practice collectively. Moreover, since the objective of the programme is to prevent the problem of child abuse and exploitation and other problems, mere dissemination of information may not help bring the desired outcome. Focusing on mere dissemination of information could be seen as disparagement of the participants' capacity to use their local knowledge. This action of facilitators was largely attributed to lack of training on facilitating skills. When they were asked about trainings, most facilitators pointed out that they took limited trainings by the help of CHAD-ET. The focuses of the trainings, however, were on how sexual abuse and exploitation could be prevented.

Inviting a large number of participants in the coffee ceremonies was one other reason that determined the communication process. Most of the facilitators invited about 25 women in a single coffee ceremony. However, more than 30 women attended all the observed coffee ceremonies. Surprisingly, almost all the facilitators thought that having 20 to 25 women for each coffee ceremony is a manageable size for discussions. On the contrary, such large numbers, if they are not divided into smaller groups, do not allow participants to undertake lively interactions. What the data verified was that facilitators were not forming smaller groups and because of this discussions were not held along the lines of what the participants' experience. Culturally, the attendants of one coffee ceremony may not exceed more than 10 people. Of course, in some special occasions such as religious holidays, coffee ceremonies may be attended 
by a large group of people. Even such settings allow participants to form smaller groups and engage on one or another kind of interaction informally. In the coffee ceremonies that this research focuses, facilitators were not trying to use strategies such as dividing large groups into smaller ones which could foster informal discussions because of this, participants were not making thorough discussions of issues raised. In such large groups the time did not allow all members of the group to take part in the discussions, had the participants been given the chance. Also, many participants were uncomfortable to speak in the presence of large audience. What is more, the data revealed that participants often met with people whom they did not know well. This also hindered some participants speaking about the issues at hand.

In general, even though the facilitators and some of the participants said that some degree of discussions were made in the coffee ceremonies, the data gathered from many of the participants of the FGDs and the observations indicated that the discussions were limited. The fact that many of the participants were not able to get the chance of taking part in the discussions showed that participation seemed to be considered as just inclusion. In view of the limited discussions and the inability of participants to make decisions on some issues it is possible to discern that the participation did not seem to be genuine as such. The nature of participation in the coffee ceremony thus goes with the first stages of Pretty's (1995) classifications of participation. Since most of the participants were passively attending what the facilitators were saying, the nature of participation in the coffee ceremonies can to some degree be categorised as passive. Passive participation is not as such important because it does not involve most participants on their own issue. What is most important is rather active participation which can help participants feel ownership of the programme. Most importantly, the nature of participation goes with what Pretty categorized as functional participation because the coffee ceremonies were used as a means to meet predetermined objectives set by CHAD-ET. Participation at these first levels made the people dependent. A relatively better participation could have taken place if the interaction of the participants had followed the existing tradition. Although the traditional coffee ceremony within which the local people function is one of the key factors for effective participatory communication, as it shows the respect of the existing and well-established culture of the 
communities, the way CADE-ET was utilising this social ritual somehow deviated from the existing tradition as a result lively discussions did not take place.

\section{Major Agenda and Ways of Setting them}

As far as setting agenda is concerned, the findings of this study attested that there were no rules that facilitators and participants could use to choose topics, determine procedures and decide on the time and date of discussions. All facilitators were opening the sessions by raising issues of sexual abuse and exploitation of children, the agenda set by CHAD-ET. As the coffee ceremonies were carried out to meet the main objective of CHAD-ET, it is not surprising if the agenda for discussions in the ceremonies usually focused on this issue. It is also evident that donors may give priority to or influence their own agenda over other crucial issues. Notwithstanding the organization's focus on the abovementioned issue, other related issues were raised in the coffee ceremonies. Almost all the facilitators and participants mentioned that topics like the rise of goods and services, child trafficking, HIV/AIDS, family law, housing problems, poverty, and income generating means were chosen by participants. All the facilitators believed that it is impossible not to raise other problems of women in the area. In this regard, the coordinator stated that other issues were raised because of two main reasons. First, the issue of sexual abuse and exploitation of children is related to a myriad of other problems such as HIV/AIDS, family law, poverty, housing problem etc. Second, some facilitators and participants sometimes raised issues that they discussed in other community conversations. During the FGDs, all participants looked convinced that 'discussing' the issue of child abuse and exploitation is very important but they also mentioned that there are other more crucial issues to be raised. What one of the FG discussants elucidated can best describe this situation:

The main reason for sexual abuse and exploitation of children is our poverty and life style. Our houses are built in such a way that one can easily get into the neighboring houses. Some of us are leading our lives by renting our beds and sleeping on the floor with our children. When we go out to search for a person who could rent our bed we usually leave our children alone or for the care of others. It is in such occasions that our children could be molested by those who rent beds or neighbours. 
This woman and other FG participants thought that poverty and housing problem were crucial issues to be dealt with in the coffee ceremonies. Sexual abuse and exploitation of children is an important issue worth discussing, but the issue did not infuse every participant's life because other pressing issues have been more pervasive. Given that their location is one of the slum areas in Addis Ababa, other major problems such as sanitation, housing, burglary etc were of the participants' interest.

Finally, allowing participants to raise other issues was one good thing worth praising regardless of the topics relevance to the main topic but the fact that the main agenda of discussion, the time span, allocation of money, places of ceremonies etc were set by CHAD-ET proved that participants were not included in the planning and designing process of the programme. Although participatory communication models allow participants of a given project to define issues of concern and suggest ways of dealing with it by themselves, this initiative did not seem to give a complete authority for participants.

\section{Representation of Participants}

The participants were mainly marginalised women in Merkato, Addis Ababa. Almost all of them were mothers. Their age ranged from 25 to 45 . But most of them were in their thirties. Most of them were housewives who were leading their life by the meager income they got from selling local drinks and Injera, a kind of bread which is Ethiopian staple food. There were also a handful of women professionals from government offices. The majority of the participants were living a life of subsistence.

Men took part in the discussions very rarely because the programme was mainly designed for women. However, most facilitators said in some occasions some men attended the ceremonies. Though the programme was especially designed for women facilitators allowed those men who wanted to take part in the coffee ceremonies. Most of the participants of the FGDs believed that men should have taken part in the discussions. They pointed out that the problems of the area could not be challenged by focusing on women only. These FG participants argued that men should also be part of this initiative as they are the ones who are mainly involved in sexual abuse and exploitation of children. Some women pointed out that they could not even participate in the 
coffee ceremonies without their husbands' permissions. Regarding men's participation, the coordinator of the initiative mentioned that the programme was especially designed for women for the reason that including men in the coffee ceremonies was difficult as most men are breadwinners of their families and spend the whole day at work. Given that the society seem to be characterised by male domination, it might have been difficult to bring the expected changes without giving due attention for the patriarchal assumptions entrenched in the society. Since most men are still decision makers of many households, it is important to enhance men's awareness about such issues.

Asked whether ethnicity and religion affected the participatory process all the FG discussants and the interviewed facilitators said that the difference that they have in religion, ethnicity and class did not affect the communication process in the coffee ceremonies. Since all the participants speak one language, there was not any problem.

\section{Conclusion and Recommendations}

The use of the Ethiopian traditional coffee ceremony can be an ideal choice for women to fight child abuse and some other problems. Such organized events may assist marginalised groups in the fight against their multi-faceted problems. CHAD-ET's attempt to make use of this traditional informal forum illustrated respect to the dignity and equality of people living in different conditions and acting in different ways, which is one of the main goals of participatory approaches (MacBride, 1998). It also exhibited that the initiative met one of the important considerations regarding participatory communication that is "initiatives for development must begin with grassroots communities and organisations" (Servaes, 1999: 93).

The finding of this study revealed that the coffee ceremony initiative provided women some

space for discussion. Though they were limited, some women spoke up their feelings and experiences of common problems in their area. In Ethiopia, where the majority of the society especially women are reluctant to speak about some unusual happenings related to sexual abuses, this initiative played an important role by providing women the chance to come together and talk about such subjects. However, the participations could not meet expectations due to the nature of 
the interaction which deviated from the traditional coffee ceremony interaction. The communication was found formal which the women were not familiar with. This made most of the women mere listeners of what facilitators and few participants spoke out. Thus, although this initiative tried to enable women to become conscious of their own cultural traditions, it appears that most of the participants did not benefit the most out of the ceremonies. Therefore, despite its contribution to limited participants the programme seemed to fail to piggyback the coffee ceremony in such a way that it could help all participants.

The limited interactions were partly attributed to large number of participants. Inviting about 30 women in the coffee ceremonies cannot ensure congenial atmosphere to have free and lively discussions. Most importantly, the interactions were limited because of facilitators' lack of skills. Though facilitators do have the knowledge of the informal nature of communication in the traditional coffee ceremony, the way they facilitated discussions in this particular case go against the tradition. This is partly due to the wrong impression that facilitators had about their role i.e. considering themselves as 'teachers' and partly because of the large number of attendants. Consequently, it is safe to conclude that the use of the traditional coffee ceremony did not foster genuine dialogues among all participants. The literature suggested that effective participation takes place when there is a shift from passive participation to an active one which allows participants to make decisions. The nature of participation in this initiative was largely in the early stages because a considerable number of women were participating by being told. The fact that participants were not involving in decision making process made obvious that participants were not empowered to make collective actions in issues of common concern. This shows that the initiative did not create solidarity and brought change among the grassroots.

In a participatory programme like this one, which has been sponsored by NGOs, the sponsor organisation try to engage some group of people in dialogue by identifying the community's problem, providing the necessary resources and skills to overcome the problem; and the goal of such programmes at the end is to help people gain control over their lives (Figueroa et al. 2002; Pretty, 1995; Wilkins, 2005). Simply put, in such initiatives it is expected that power shifts from the control of external institutions or administrators to that of target communities. Although this 
initiative has been running for two years, no attempt was made by the community to own the programme and run by their own. This shows that participants somehow developed a sense of dependency on the sponsor organisation.

Regarding discussion topics, despite the agenda of discussions were mainly about sexual abuse and exploitation of children, other issues were raised as topics. These issues were raised because, for one thing, they are related to sexual abuse and exploitation and for another, participants prioritised other issues over the issue that the runner of this initiative usually set. Whatsoever the case, this can, to some extent, demonstrate the exclusion of participants at the early stages of the designing and planning process. Had participants been given the chance to take part in the designing and planning stages, they could have prioritised other issues over what the sponsor organisation set. The fact that CHAD-ET called the participants after deciding the agenda indicated that participation was mainly used as a means to achieve predetermined objectives.

Finally, while some of the findings showed that there are some encouraging developments in the utilisation of the coffee ceremony for participatory communication, many other findings suggested that a lot more should be done for the proper utilisation of this cultural ritual for social change. The following recommendations will help improve this and other similar programmes.

- Utilising group media such as the coffee ceremony for development communication initiatives requires an intimate knowledge of the nature of traditional communication. Therefore, programme designers, coordinators and facilitators of such programmes need to make discussions following the existing cultural traditions in such a way that benefits all participants. Utilisation of the pre-existing coffee groups or forming new groups which include intimate neighbours with manageable group size will possibly help foster lively and informal interactions.

- In development communication initiatives like this one, the nature of participatory communication is to a great extent determined by facilitators' skill. Hence, facilitators need to be trained not only about the issues that they address but also on the skills of fostering discussions and dialogues in line with the cultural context that the target community has been following. 
- Programme designers and implementers need to look into the underlying assumption of participatory communication. They especially need to emphsise participation at all levels that could help them include the thoughts of participants in the different stages of the project including the planning and designing stages.

- Such programmes focusing on participatory communications should focus on giving power for participants. This would help women to develop their decision making skills and have control over their lives. It also helps them keep arranging coffee ceremonies by themselves and figure out other common problems of their area.

- Although women should be empowered to solve their problems on their own, allowing men to assume responsibilities in some issues, where their contributions are felt, would make such initiatives more successful. As suggested by many of the study subjects, it would be quite useful to involve men in the coffee ceremonies.

- The utilisation of a cherished and well-established social ritual such as the coffee ceremony does not necessarily guarantee active participation. Continuous assessment and evaluation of the programme will help to identify the major strong and weak sides. Hence, making use of the strong sides and ameliorating the gaps will improve the participatory communication.

- Finally, in countries like Ethiopia, where there are deep-rooted and long-established cultures of getting-together and unraveling problems through traditional means, the use of the coffee ceremony need to be promoted and supported. The utilization of such methods, however, should go in line with the existing tradition. 


\section{References}

Agarwal, B. (2001). Participatory Exclusions, Community Forestry, and Gender: An Analysis for South Asia and a Conceptual Framework. World Development, Vol. 29, No. 12, (pp.1623-1648).

Arnst, R. (1996). Participation Approaches to the Research Process. In Servaes, J; Jacobson, T L; White S A. (eds.), Participatory Communication for Social Change. (pp. 109-126). New Delhi: Sage Publications.

Bessette, G. (1996). Development communication in West and Central Africa. In Bessette, G. \& Rajasunderam C. V. (eds.), Participatory development communication: a West African agenda: Towards a research and Intervention Agenda. (pp. 9-36) International Development Research Center. Ottawa: Southbound Penang.

Bessette, G. (2004). Involving the community: a guide to participatory development communication. Southbound: Ottawa.

Bloor, M.; Frankland, J.; Thoamas, M.; Robson, K. (2001). Focus group in social research. UK: Sage publication.

Boafo, K. (2006). Participatory development communication: an African perspective. Retrieved August 23, 2009, from http://www.idrc.ca/es/ev-104968-201-1-

DO_TOPIC.html\#ch03en01

Carmen, R.E. (1989). Development Communication: the Search for a Participatory Paradigm. Community Development Journal, Vol. 24, No.4, (pp.264-272).

CSA-Ethiopia \& ORC USA. (2005). Ethiopia demographic and health survey. Addis Ababa, Ethiopia.

Dagne, H. G. (1994). Early marriage in northern Ethiopia. Reproductive Health Matters: Motherhood, Fatherhood and Fertility, 4, 35-38.

Dagron, A. G. (2001). Making waves: Participatory communication for social change. New York: The Rockefeller Foundation.

Diouf, J. (1995). FAO Statement, Connections April: 8.

Duraiappah, A. K.; Roddy, P. and Parry, J. (2005). Have Participatory Approaches Increased Capabilities? International Institute for Sustainable Development (IISD). Retrieved October 12, 2009, from http://www.iisd.org/pdf/2005/economics_participatory_approaches.pdf 
Figueroa, M. E., Kincaid, D. L., Rani, M., \& Lewis, G. (2002). Communication for social change: An integrated model for measuring the process and its outcomes. New York: The Communication for Social Change Working Paper Series No. 1, The Rockefeller Foundation.

Finch, H. and Lewis, J. (2003). Focus Groups. In Ritchie, J. and Lewis, J. (eds.), Qualitative Research Practice: A Guide for Social Science Students and Researchers. London: Sage Publications.

Fraser, C. \&Villet, J. (1994). Communication in practice. In Fraser, C. and Villet, J. (eds) Communication: A Key to Human Development, United Nations Food and Agriculture Organization, Rome, (pp.8-23)

Huesca, R. (2008). Tracing the History of Participatory Communication Approaches to Development. In Servaes, J. (ed.) Approaches to Development (pp.180-200).Los Angeles: Sage publications.

Jacobson, T. L., \& Storey, J. D. (2004). Development communication and participation: Applying Habermas to a case study of population programmes in Nepal. Communication Theory.Vol.14, No.2, (pp.99-121). Retrieved October 15, 2009, from http://www3.interscience.wiley.com/cgi-in/fulltext/118799179/PDFSTART

Khadka, N. B. (2000). Participatory communication as an alternative paradigm for nutrition communication in Nepal. Retrieved September 08, 2009, from http://www.eric.ed.gov/ERICDocs/data/ericdocs2sq1/content_storage_01/0000019b/80/1 6/12/90.pdf

Kottak, C.P. (1991). When people don't come first: Some sociological lessons from completed projects. In M. Cernea, Editor, Putting People First (Second edition ed.). Oxford University Press. (pp. 431-464).

Maria, C. and Peruzzo, K. (1996). Participation in Community Communication. In Servaes, J. et al. (1996). Participatory Communication for Social Change (pp. 162-179). New Delhi: Sage Publications.

Mefalopulos, P. (2008). Development Communication Sourcebook: Broadening the Boundaries of Communication. Washington: World Bank Publications.

Melkote, S. R. (1991). Communication for Development in the Third World: Theory and Practice. London: Sage Publications.

Melkote, S. R. \& Steeves, H. L. (2001). Communication for Development in the Third World. New Delhi: Sage Publications. 
Mlama, P. (1991). Women's participation in communication for development: The popular theater alternative in Africa. Research in African Literatures, Vol. 22, No.3, (pp.41-53).

Mlama, P. (1994). Reinforcing Existing Indigenous Communication Skills: The Use of Dance in Tan- zania'. In Riano, P. (ed.) Women in Grassroots Communication: Furthering Social Change. (pp.51-64). London: Sage Publications.

Moemeka, A. (1997). Development Communication for Developing Societies: Facing the Realities. International Communication Gazette. Vol.59, No.4-5. (pp. 59- 379)

Narayan, D. (1995). The Contribution of People's Participation: Evidence from 121 Rural Water Supply Projects. Environmentally Sustainable Development Occasional Paper Series No.1, the World Bank, Washington.

Parfitt, T. (2004). The ambiguity of participation: a qualified defense of participatory development, Third World Quarterly, 25: 3, 537- 555. Retrieved September 05, 2009, from http://pdfserve.informaworld.com/78518_731201505_713632716.pdf

Pretty, J. N.; Guijt, I.; Thompson, J. and Scoones, I. (1995). Participatory learning and action: $a$ trainer's guide. London: IIED.

Riano, P. E. (1994). Women in Grassroots Communication Furthering Social Change. Thousand Oaks, CA: Sage Publications

Rietbergen-McCracken, J. (Ed.) (1996). Participation in practice: the experience of the World Bank and other stakeholders. Discussion paper no. 333, World Bank, Washington DC. Retrieved September 05, 2009 from http://wwwwds.worldbank.org/external/default/WDSContentServer/WDSP/IB/1996/12/01/00000926 5_3970716145150/Rendered/PDF/multi_page.pdf

Rogers, E. M. (1976). Communication and Development: The Passing of the Dominant Paradigm. Communication Research, Vol. 3, No. 2, (pp. 213 - 240). Retrieved November 02, 2009, from http://crx.sagepub.com/cgi/reprint/3/2/213

Servaes, J. (1999). Communication for Development. One World, Multiple Cultures. Cresskill: Hampton Press.

Servaes, J. (2008). Communication for development and social change. London: Sage Publications.

Servaes, J. \& Malikhao, P. (2007). Communication and Sustainable Development. In Servaes J. and Liu, S. (eds.), Moving Targets. Mapping the paths between communication, technology and social change in communities, Southbound, Penang, (pp. 11-42). 
Stauart, S \& Bery, R. (1996). Powerful Grass-roots Women Communicators: Participatory Video in Bangladish. In Servaes, J; Jacobson, T. L; White S. A. (eds.), Participatory Communication for Social Change. (pp. 197-212). New Delhi: Sage Publication.

Tufte, T \& Mefalopulos, P. (2009). Participatory Communication: A Practical Guide World Bank Working Paper No. 170. Washington DC.

Ugboajah, F.O. (1972). Traditional Urban Media Model Stocktaking for African Development: Role of Traditional Communication. In Gumucio-Dagron, A. \& Tufte(eds) Communication for Social Change Anthology: Historical and Contemporary Readings. 2006. (pp. 59-62) Communication for Social Change Consortium, Inc.

UNICEF. (2001). Early marriage, child spouses. UNICEF Digest No. 7, 1-28.

Waisbord, S. (2001). Family Tree of Theories, Methodologies and Strategies in Development Communication: Convergences and Differences. New York: The Rockefeller Foundation, Retrieved September 02, 2009, from http://www.comminit.com/pdf/familytree.pdf

Wilkins, K. G. (2005). Out of focus: gender visibilities in development. Retrieved September 02, 2009, from http://bibliotecavirtual.clacso.org.ar/ar/libros/edicion/media/21Chapter15.pdf

White, R. A. (2008). Ten major lines of research on grassroots, participatory communication in Africa. African Communication Research 1(1), pp. 11-45.

Yoon, C. S. (1996). Participatory communication for development. In Bessette, G., and Rajasunderam, C.V. (eds.), Participatory development communication: A West African agenda. Ottawa: International Development Research Centre/Penang, Malaysia: Southbound Press. 